Raynaud's phenomenon, sclerodermatous skin changes, and osteolysis of the distal phalanges was confirmed in several investigations of autoclave workers in Canada and the USA, medical surveys showing an incidence of $3-5 \%$ and suggesting that the disorder was largely confined to autoclave or reactor cleaners exposed to the VCM gas. ${ }^{23}$

In 1974 an association was reported ${ }^{4}$ between exposure to VCM and a rare liver tumour-angiosarcoma-in men who had worked as autoclave cleaners in the first stage of the polymerisation process. Carcinogenic liver changes had been reported $^{5}$ in 1971 in rats exposed to a dosage of 30000 ppm vinyl chloride monomer, but that level of exposure was so high that its importance for man had been disregarded. Further testing, however, in 1973 by Maltoni ${ }^{6}$ in Italy confirmed that liver cancer occurred in animals at exposures as low as 250 ppm. Since 1974 there have been 48 reported cases of angiosarcoma associated directly with VCM, two of them in Britain.

When the results of the early studies and the plant data from the US were sent to HM Factory Inspectors and Employment Medical Advisors monitoring of the six British VCM plants began at once. A time-weighted threshold limit value of $50 \mathrm{ppm}$ in the working environment was imposed. The Health and Safety Executive issued a comprehensive code of practice in February 1975 as a result of the formation of a joint working group of the Inspectorate, unions, and employers. In October 1975 a new hygiene standard was adopted: a ceiling level of $30 \mathrm{ppm}$; a time-weighted threshold limit value for VCM of $10 \mathrm{ppm}$; and a policy that, wherever practicable, exposure of workers should be brought as near as possible to zero concentrations. In all the history of occupational medicine there has never been a better example of a swift co-operative reaction to evidence that a hitherto unsuspected process carried carcinogenic risks. To evaluate the extent of the hazard within Britain three studies have been set up: a prospective study of PVC manufacturers; a prospective study of PVC fabricators (about $5 \mathrm{ppm}$ of VCM is retained in the PVC and is available for release during subsequent processing); and a retrospective study of primary angiosarcoma. The present evidence points to a latent interval of from 12 to 29 years (mean around 20 years) with a mean duration of exposure of 18 years.

As yet we have no established screening procedure for the early detection of angiosarcoma. Nevertheless, a standard medical examination procedure has been formulated to try to identify early cases or susceptible workers, including estimation of liver transaminases, alkaline phosphatases, and bilirubin, a platelet count, and urine analysis. By arrangement with family doctors individuals with persistently abnormal liver tests are being referred to the appropriate consultant. Preliminary results in a recent study ${ }^{7}$ of 1357 workers showed no obvious liver disease due to VCM exposure. There has, however, been some difficulty in interpreting liver function tests, in dealing with false-positives, and in differentiating other pathological conditions such as alcoholism. The value of invasive techniques such as liver biopsy is also being questioned, and attention is being focused on grey-scale ultrasonography as a possible acceptable alternative. Emphasis has meanwhile shifted from biological testing to more stringent control of factory exposure, ensuring that conditions conform to the most recent threshold limit value of $10 \mathrm{ppm}$. It may well be that the angiosarcoma cases now presenting are the result of previous exposure to high concentrations of VCM, and some evidence ${ }^{8}$ suggests that polymerisation workers may have been exposed to concentrations as high as $1000 \mathrm{ppm}$ VCM in the $1950 \mathrm{~s} ; 400-500 \mathrm{ppm}$ in the 1960s; and 100-150 ppm in 1973 and 1974.
Surveys now in progress will confirm whether the new limits for exposure to this chemical carcinogen have eliminated any further health risk. This example of a hitherto unsuspected health hazard in a familiar material should act as a warning to a!l chemists and toxicologists and adds weight to the wise advice of Ramazzini, ${ }^{9}$ who in 1700 pleaded with his physician colleagues to inquire during the course of their medical examinations, "What trade do you follow ?" Already our industries are trying much harder to achieve the new hygiene standards, to set up routine monitoring of the working environment, and to provide medical supervision of the work force.

${ }^{1}$ Cordier, J M, et al, Cahiers de Médecine du Travail, 1966, 4, 3.

Wilson, R H, et al, fournal of the American Medical Association, 1967, 201, 577.

3 Dinman, B D, et al, Archives of Environmental Health, 1971, 22, 61.

${ }^{4}$ Creech, J L, and Johnson, M N, Fournal of Occupational Medicine, 1974, $16,150$.

Viola, P L, Bigotti, A, and Caputo, A, Cancer Research, 1971, 31, 516.

${ }^{6}$ Maltoni, C, Crespi, M, and Burch, P J R, eds Excerpta Medica International Congress Series no 275. Amsterdam, Excerpta Medica, 1973. Duck, B W, Proceedings of the Royal Society of Medicine, 1976, 69, 307. - Barnes, A W, Proceedings of the Royal Society of Medicine, 1976, 69, 277. ${ }^{9}$ Ramazzini, B, De Morbis Artificium Diatriba. Modena, Capponi, 1700.

\section{Cancer of the oesophagus}

About 2500 patients die each year in Britain from oesophageal cancer, the incidence being 50 per million. As a rough estimate from published reports, ${ }^{1}$ of 100 patients with the disease (mostly men over 60) 80 will present with dysphagia, but 20 will never have had any difficulty swallowing. Fifty have pain in the chest or upper abdomen. Regurgitation, hoarseness, or respiratory difficulty is rarer. On average before the patient seeks medical advice symptoms last five months, and the average loss of weight is about $10 \mathrm{~kg}$. In hospital about 40 will have evidence of distant tumour spread, but 60 will appear to have operable growths and resection will prove possible in 50. The operative mortality lies between $10 \%$ and $20 \%$, so that only 40 may expect to leave hospital having had their tumour resected. Twenty will die in the first year and only five will survive for five years.

Pessimists may well wonder from these statistics whether it is worth treating the disease at all: but treatment aims at both increasing the survival time (quantity of the remaining life) and relieving distressing symptoms (quality). This explains why radical radiotherapy is preferred for mid-oesophageal cancers, since the mortality is lower than with surgery and most patients will be given symptomatic relief for one year. Radiotherapy also gives good palliation, with or without the insertion of tubes to enable saliva and fluid nutrition to be swallowed. Results are poor in so many cases because the growths are so extensive. If the tumour can be removed the five-year survival is $10 \%$, if the tumour is less than $4 \mathrm{~cm}$ long this increases to $20 \%$, and if there are no local lymph nodes diseased the five-year survival is $40 \%$. Early diagnosis is of utmost importance.

General pathological principles explain why symptcms occur so late. Circumferential tumours cause obstruction, but asymptomatic growth may easily occur in a hollow distensible organ. In the stomach, presentation of growths at the pylorus and cardia is early compared with those in the body. Similarly in the oesophagus lesions of the cardia and postcricoid region present earlier than those in the body, which either proliferate 
into the lumen or extend longitudinally, but rarely circumferentially. The spiral arrangement of the muscle may account for this. ${ }^{2}$

Can screening achieve an earlier diagnosis? Yes, but in a disease as rare as 50 per million the effort required would be disproportionate-and it is not yet thought justifiable for carcinoma of the stomach, which in Britain is more than twice as common. In Japan, where stomach cancer occurs in 700 people in every million, the results of fibreoptic screening have been rewarding. There are two high risk areas for cancer of the oesophagus: ${ }^{3}$ the border of the Caspian ${ }^{4}$ in Iran $(2620$ million $)$ and south of the Taihang Mountains in Northern China (1090 million). The disease has been known in this latter area for centuries," the incidence is stable, and it does not seem to be connected in this environment with alcohol and tobacco. The inhabitants eat bread, not rice, but pickled cabbage mixed with the fungus Geotrichum candidum is their "sauerkraut." Gastronomy may not explain everything: Chinese hens have the disease as well. In this population cytological screening of cells removed by a net covered balloon ${ }^{6}$ has led to the recognition of very early cases and a precancerous dysplasia. ${ }^{7}$ The resection rate has increased to $80 \%$, operative mortality decreased to $4 \%$, and the five-year survival rate increased to $29 \%{ }^{8}$

The results show how important early diagnosis is in oesophageal cancer and that good results can be obtained in centres which have a special interest. When dysphagia occurs as a symptom in general practice it should be investigated radiologically with as much urgency as bleeding from any orifice. Chairman Mao also believes in prevention, but this will be possible only when the aetiology of the disease has been unravelled.

${ }^{1}$ Earlam, R, Clinical Tests of Oesophageal Function. St Albans, Crosby Lockwood Staples, 1976.

2 Stelzner, F, and Lierse, W, Thoraxchirurgie, 1966, 14, 559.

3 Day, N E, Cancer Research, 1975, 35, 3304.

${ }^{4}$ Hormozdiari, H, et al, Cancer Research, 1975, 35, 3493.

Chinese Medical fournal, 1975, 1, 167.

Chinese Medical fournal, 1976, 2, 113.

'Chinese Medical fournal, 1975, 1, 110.

${ }^{8}$ Chinese Medical fournal, 1975, 1, 60.

\section{Double departure}

"Dr Stevenson assumes office at a time of some unrest and anxiety in the profession," said the softly worded $B M F$ leading article ${ }^{1}$ noting Dr Derek Stevenson's arrival in 1958 in one of medicine's most influential posts: Secretary of the British Medical Association. Eighteen turbulent years later we could note with equal understatement: "Dr Stevenson leaves office at a time of some unrest and anxiety in the profession."

In that time Derek Stevenson's name has become synonymous with that of the BMA and his face and voice have become familiar to a national audience. In an age that demands instant, authoritative comment Dr Stevenson has more than held his own in the public arena of press and television, and with politicians so sensitive to the media this has proved an invaluable asset for the profession. Few of us can know the time and energy demanded from an individual in the public eye. Despite these demands Derek Stevenson has managed not only to administer a sizable and often tempestuous organisation but also to devote his considerable diplomatic talents to the "off stage" activities essential to the effectiveness of national institutions like the BMA.

The Secretary always works very closely with the Chairman $\stackrel{\mathbb{2}}{\stackrel{2}{c}}$ of Council-and since this is an arranged marriage rather than a love match the divorce rate has been remarkably low. Derek $\stackrel{\bar{S}}{\stackrel{5}{9}}$ Stevenson has served under five chairmen and by coincidence his final chairman, $\mathrm{Mr}$ Walpole Lewin, is also bowing out $\frac{\mathrm{O}}{\overline{\mathrm{N}}}$ with him. It is a constant surprise how such an onerous $\frac{\text { }}{\vec{\sigma}}$ "voluntary" post as that of Chairman of Council can be $\varnothing$ combined with clinical responsibilities. Yet $\mathrm{Mr}$ Lewin, an eminent neurosurgeon, has for five years somehow managed $\overrightarrow{0}$ to cope with a burdensome and increasingly unpredictable $\overrightarrow{-}$ medicopolitical timetable as well as doing his lists in the ${ }_{0}$ operating theatre. Walpole Lewin's "normal" BMA duties have के been added to because his term of office has coincided with the $\frac{3}{\mathrm{~N}}$. Association's three-year stint servicing the Standing Committee os of Doctors of the EEC. So as president of the standing com- N mittee he has played a big part in the sensitive international $\stackrel{\infty}{\oplus}$ discussions that led up to agreement on the free movement $\omega_{\sigma}^{\omega}$ of doctors within the EEC. He has also championed the cause $\frac{\text { ? }}{2}$ of the junior doctors in the Common Market. On the domestic $\vec{V}$ front he has faced pay policies and pay-bed rows, contract $c$ disputes and the Merrison inquiry, NHS reorganisation and $\rightleftharpoons$ BMA constitutional reform: the list of the crises for which $\overrightarrow{0}$ he has had to stand to would fill the page. He has skilfully piloted the BMA through them and every eight weeks or so he has had the delicate task of shepherding the Council through an overloaded agenda: looking back he may well regard this latter activity as perhaps his most taxing one.

Indeed too many doctors gladly turn their backs on medico- $\stackrel{\mathbb{D}}{\mathscr{Q}}$ politics, persuading themselves, no doubt, that as practising $\overrightarrow{\vec{O}}$ clinicians the periodic bitter disputes between the profession 3 and the State are not really their concern. They are wrong: but doctors are fortunate that Dr Stevenson's experience as an? insider in Whitehall before coming to the BMA has stood him in good stead during 30 years spent patrolling the restless frontier between medicine and politics. His achievements have $\frac{\sigma}{3}$ been formidable, as recognised by the well-deserved presentation to him in Dublin (last month) of the Association's Gold Medal (p 192). But there must have been occasions when the Secretary felt he was patrolling on his own. The profession's propensity for internal disagreement has caused the BMA severe difficulties and both the Chairman of Council as referee $\frac{D}{O}$ and the Secretary as the public presenter of the Association's policies have been the target for showers of brickbats in recent years. They have weathered all this and, indeed, per- $-\omega$ haps it has been this experience that has motivated their emphasis on the need to keep doctors united. If the profession fragments then the politicians and bureaucrats will play havoce with medicine. It is a message that Derek Stevenson and Walpole Lewin have ceaselessly impressed upon all those, staff and elected representatives alike, who work at BMA House.

In a message to the profession on p 190 Dr Elston Grey-O Turner, who succeeds Dr Stevenson as Secretary, also urgeso doctors to unite. We wish him all success in a post for which hiș predecessor has set such demanding standards.

${ }^{1}$ British Medical fournal Supplement, 1958, 2, 1283. 